\title{
Entrevista: CHARLES WAGLEY
}

por José Carlos Sebe Bom Meihy

\section{VISITA AO VE LHO SENHOR: CHAR LES WAG LEY}

A geração que passou pela universidade brasileira nas décadas de 60 e 70, acabou por viver uma situação ambígua em face à aceitação dos Estados Unidos.

Fora do campus, o contexto sócio-econômico promovia uma aceleração do desenvolvimento urbano-industrial que projetava o país dos norte-americanos como modelar. Shoppings Centers, cursos de inglês, o bárbaro esquema turístico que se fazia em torno do mundo de Disney, a vulgarização das $T$ shirts, tudo motivava a classe média emergente a aderir perifericamente aos hábitos tidos como típicos da cultura estadunidense.

No campus acadêmico, variava a atitude comum. Ao universitário cabia refutar veementemente tudo que vinha de fora, especialmente se a inspiração emanava das terras do Tio Sam. Certamente, não era de bom tom, dentro das fronteiras universitárias, gostar do cinema, da música, das roupas americanas. Tudo que lembrasse os Estados Unidos deveria ser motivo de ridicularização e ódio. Afinal, mesmo antes de ser noticiada pelo Washington Post, em 1975, a Operação Brother Sam era evidente e ninguém tinha dúvidas do apoio do governo norte-americano dado aos militares em 64. A universidade brasileira em geral, muito particularmente a USP reagiu à atitude governamental norte-americana e desenvolveu-se em certos círculos uma aversão acentuada, particularmente à produção acadêmica dos scholars brasilianistas.

Por volta de 1971, a aversão aos acadêmicos norte-americanos na universidade ganhou tanta intensidade que brasilianista deixou de ser um conceito abrangente e passou a significar apenas a produção dos intelectuais norte-americanos que escreviam sobre o Brasil. Então, uma resposta indignada se formulava sobre vários aspectos da invasão intelectual promovida pelos Estados Unidos.

É claro que as situações circunstanciais daqueles momentos se emendavam no continuado discurso antiimperialista e nutriam o nacionalismo acadêmico que deveria refutar as explicações exóticas e ao lado de um complexo xenofobismo, evidenciar que a nós cabiam as 
explicações de nossa vida sócio-cultural. Meios jornalisticos e artísticos engrossavam as fileiras dos opositores à invasão acadêmico-cultural dos Estados Unidos.

Dada à censura e ao insuportável clima de intolerância ao comunismo, tecer críticas aos Estados Unidos implicava em subversão, assim, o nacionalismo acadêmico se fez em discursos orais, em rejeições teóricas e sempre indiretamente. Aliás, quem mais percebeu estas questões e as devolveu ao público foram os jornalistas.

Em 1971, a revista Veja, no número de novembro, publicava numa reportagem de fundo, "A história do Brazil: o passado do país está sendo escrito em ing/ês" Élio Gaspari tornava então público o debate, denunciando ambiguamente, o que era óbvio na universidade. A revista Veja, em seu número de março de 76 , novamente trouxe o tema às primeiras páginas, só que desta vez de maneira positiva: homenageando Charles Wagley, numa entrevista que trazia um título simpático e sugestivo "Uma paixão pelo trópico, o decano dos brasilianistas fala de 37 anos de estudos sobre um pais que o desconhece"; o texto é assinado por Nirlando Beirão. Entre o texto de Gaspari e o de Beirão havia uma enorme distância. $O$ primeiro denunciava, o segundo prestava reverência, e, nesta variação, havia também a mudança de atitude do governo norte-americano.

Sem entrar no feroz debate (tão caro a Noan Chomsky) sobre o cinismo da política de Carter, convém lembrar que, ao Brasil, a investida norte-americana em favor dos direitos humanos abria intervalos no fechamento político-ditatorial. Sensivelmente, o contexto universitário deixava também vazar uma tolerância maior ao brasilianismo, e assim, inauguravam-se possibilidades de avaliações amplas sobre o brasilianismo.

Nos meios estritamente acadêmicos, o brasilianismo foi percebido pela primeira vez por José Honório Rodrigues e Francisco de Assis Barbosa, em 1969; nos textos destes autores o fenômeno era apenas percebido. Espelhando a ojeriza comum à maioria da massa acadêmica uspiana, em 72, Dulce Helena Álvares Pessôa Ramos elaborou seu mestrado sob o tema Um exemplo de Pesquisa Bibliográfica como elemento de pesquisa pública: as teses americanas sobre o Brasil (1960-1970), aí a sugestão do que o trabalho intelectual desenvolvido sobre a cultura e história brasileiras serviria de base para a ação governamental de Washington.

Em 1978, a publicação do número 4 da série Tudo é História: cadernos de pesquisa, da Editora Brasiliense, trazia o título "Coke: será que devemos beber história como bebemos Coca-Cola?" Neste número, artigos, entrevistas e resenhas deixavam claras as diversida- 
des de opiniões. Por esta época, iniciava uma pesquisa buscando entender melhor o significado do brasilianismo e, então, resolvi passar um questionário aos elementos das diversas gerações de brasilianistas, perguntando entre outras coisas, sobre o significado de se estudar o Brasil, bem como o porquê. As respostas foram prontas e era raro o questionário que não se referisse à influência de Charles Wagley.

Intrigado pelas aproximações que se fazem entre a figura de Wagley e a personagem criada por Jorge Amado em Tenda dos Milagres, pensei que nenhum trabalho poderia ser feito. sem antes compreender a ação deste mestre, afinal o $d r$. Levenson, realmente desafiava a fantasia geral.

Em 1983, num frio janeiro, consegui nos Estados Unidos marcar uma entrevista com o Velho Senhor. Uma legião de discípulos dele e amigos comuns se colocou entre nós, facilitando tudo.

Minha aventura começou em Miami, onde, num pequeno avião, rumei para Gainsville, para a Universidade da Flórida. Estava ansioso, e meu lado acadêmico se confundia na estruturação das perguntas a serem feitas na entrevista.

Chovia muito quando cheguei. O vento era assustador e, no pequeno aeroporto, vi-me perdido entre desconhecidos. Aos poucos, as pessoas que nos cercavam foram se afastando e ficamos sós. Nós dois parados, identificando-nos. Cigarro na mão, sorriso largo e amigo, Wagley se aproximou dizendo, num cansado, mas bom português: "Tem que ser você, não há mais ninguém" Confesso que Wagley dirigia mal e logo pensei que ele deveria ter trocado Nova lorque por Gainsville, também pelo trânsito.

Chegamos ao escritório dele, e começamos a entrevista. Ambos estávamos emocionados, ele por falar do Brasil, eu por ouvi-lo. Entrevistar Charles Wagley foi um dos grandes privilégios que a vida acadêmica me possibilitou.

A conversa foi gravada, durou noventa minutos e quando acabou, nosso colega, José de Souza Martins, que estava como professor visitante na Universidade da Flórida, nos acompanhou para o almoço. Quando deixamos o restaurante, o sol brilhava e o vento mudara o rumo.

Guardei por muito tempo esta entrevista. Achei que deveria esperar por um momento adequado para publicá-la, pois creio que ela não deve simplesmente ser interpretada à luz do debate historiográfico. Esperei que os ânimos se amainassem e recortei alquns trechos onde a ordem sentimental impôs discrição, afinal, como disse Wagley, "o Brasil está ligado às coisas mais íntimas que a vida me deu" 
SEBE: Professor, há atualmente um grande interesse por se descobrir onde e quando nasceram os estudos sobre a América Latina.

WAGLEY: A América Latina sempre foi um pedaço do mundo desconhecido pelos norte-americanos, países como - Brasil não faziam parte do gosto dos pesquisadores daqui, mas nos anos 30 , isto começou a mudar. A grande dificuldade era a língua. Quase não havia universidade que ensinasse português. Da cultura brasileira, nem se fala, havia meia dúzia de pessoas interessadas.

SEBE: Na sua opinião, quem iniciou os estudos sobre a América Latina?

WAGLEY: O pioneiro foi John Frederic Normano. No começo da década de 30 (1931), publicou em inglês The Strugle for South America; ele morou e ensinou no Brasil e foi quem começou a moderna historiografia sobre a América Latina. Antes dele, havia o Roy Nash, que publicou The Conquest of Brazil, em 26. Ah! Havia uma pessoa muito importante para todos nós, o William Varian. Varian era um professor de literatura, mas muito interessado pelo ensino de português. Ele trabalhava com a Fundação Rockefeller, e era um sujeito que falava bem português e espanhol. Ele era muito versátil e distinguia os sotaques do espanhol da região do Pla- ta, do México e da Colômbia. Ele era muito amigo do Luis Borba de Moraes. Houve também o primeiro colóquio lusobrasileiro, que eles organizaram em 41, em Washington. A grande figura neste colóquio foi o James Preston, o geógrafo. Eu não fui neste encontro porque estava no Brasil.

SEBE: Quando o senhor foi ao Brasil?

WAGLEY: Eu fui em 39 e fiquei até 40; voltei por um ano, aqui, em $40 / 41$ e, pela metade de 41, voltei e lá fiquei durante toda a Guerra. Antes da Guerra, eu já estava trabalhando no Museu Nacional, no Rio de Janeiro. Foi bom, porque antes de ir para lá, fui instrutor na Universidade de Columbia e foi em Nova lorque que começou a se formar um grupo interessado em estudar o Brasil. Com o in ício da Guerra, o Brasil tornou-se importante, porque ficou do lado dos aliados e todos os que falavam português ou tinham viajado pelo Brasil prestaram serviços como observadores. Com isto, organizou-se o grupo de pessoas interessadas no Brasil.

SEBE: $O$ senhor acha, então, que a Guerra foi um dos elementos aglutinadores de brasilianistas?

WAG LEY: Foi um deles. O Brasil era o maior aliado dos Estados Unidos. Havia pouca gente que conhecia aquele país importante e misterioso, e era preci- 
so ajudar durante a Guerra, em várias tarefas. Eu, por exemplo, trabalhava em saúde pública; alguns tinham outras obrigações, como traduzir jornais. Mas não foi só a Guerra, não. O tempo do Brasil havia chegado. Olha, o Brasil é o maior país da América do Sul, é maior que os Estados Unidos em território contínuo, e muito interessante histórica e culturalmente. Não era só a Guerra, não. Não podemos esquecer que antes havia os esforços de Mary W. Williams, Percy A. Martin, Dana Munro. Estes pesquisadores continuaram a obra pioneira de Herbert Bolton.

Com a Guerra, a academia americana começou a perceber que não cumpria seu papel. Por volta de $48,48 / 49$, os Estados Unidos perceberam que só havia pouco conhecimento da Rússia, China, India. Foi em 49 que o Social Science Research Concil criou um comitê de estudos de áreas (Area Studies) e, uma destas regiões era a América Latina, onde o país mais visado era o Brasil.

SEBE: Então, antes da América Latina, organizaram-se os estudos sobre a União Soviética, Ásia.

WAGLEY: $\bar{E}$, mas eram institutos miseráveis. $O$ americano era voltado para estudar os Estados Unidos, assim mesmo poucos aspectos da própria história. No mais, havia os China hands. China hand era um missionário ou pessoa que aprendeu chinês por acaso; depois de 48, resolveram fundar uma área de estudos baseada na China e então os China hand cederam lugar a sofisticados scholars. Este sistema se desdobrou e, já por volta de 1960, o governo e as fundações ajudaram a criar centros visando ajudar os estudos da América Latina.

SEBE: E quando o senhor apareceu nesta cena?

WAG LEY: Foi em 60, quando eu criei, em Columbia, o Instituto de Estudos Latino-Americanos. Você deve lembrar que, naquele tempo, o Instituto teve 32 bolsas de estudo de pós-graduação. Hoje em dia, é ridículo pensar que se formos muito bem-vistos, podemos vir a ter seis ou oito. Outro dia, eu fiz um levantamento de quantos bolsistas de Columbia foram para o Brasil no meu tempo e listei 63, como Bradford Burms, Ralph della Cava, Herbert Klein, Riordan Roett. E importante lembrar que Columbia sempre dava um jeitinho de destinar as bolsas quase que só para o Brasil.

SEBE: Então, professor, houve uma pré-história do brasilianismo, iniciada antes da Segunda Guerra, depois houve uma outra fase importante, advinda do impacto da Guerra, e a terceira fase pode ser determina- 
da a partir de Castro e da revolução cubana?

De outra forma, seria válido pensar que os novos brasilianistas são só filhos de Castro?

WAGLEY: E. existem duas brincadeiras, na verdade. Uma é que diz que todos somos fiIhos de Castro e que ele produziu a oportunidade de estudos e bolsas. Mas existe também uma outra versão, que diz que foram os latino-americanistas que prepararam, nos Estados Unidos, o caminho de Castro. Logicamente, isto é um exagero, mas o fato é que Castro influiu diretamente na ação do governo, as fundações Ford, Rockefeller e Carnegie já estavam nas paradas, antes.

Estou dizendo que as fundações devotaram atenção à América Latina antes do governo. Elas foram realmente importantes porque notaram o vácuo, a falta de estudos sobre vários países do mundo e então perceberam a necessidade de formar especialistas em várias disciplinas. O conceito de Area Studies não pode ser visto apenas como recurso geopolítico. Não. Ele tinha um sentido intelectual. Depois, o caso de Cuba ajudou, pois mostrou a necessidade de renovar a política de educação e o governo decretou o National Defense Educational Act; com esta legislação, as seguintes línguas foram declaradas urgentemente necessárias: russo, chinês, ja- ponês, árabe e português. Isto foi de enorme ajuda para a nossa proposta.

Alguns centros de pesquisa beneficiaram-se muito com o ato do governo; creio que o primeiro favorecido foi a F̂̀lórida, depois Columbia e Wisconsin... acredito que o Texas só veio depois da Universidade da $\mathrm{Ca}$ lifórnia, Los Angeles.

SEBE: $O$ papel da Universidade de Columbia sempre foi muito importante, não?

WAGLEY: Sim. Columbia foi muito importante, mas antes nós temos que pensar no grupo da Califórnia, de Stanford. Lá havia a equipe que convidou o Oliveira Lima. Columbia se destacou numa segunda fase. Columbia ficou imponente porque tinha pesquisadores de vanguarda, como Roy Nash, Frank Tannenbaun, Franz Boas. Tinha até o Gilberto Freyre passando por lá.

No fim de 58, o Tannenbaun me ajudou a começar a organização do Instituto. Logo, porém, o Tannenbaun se aposentou e, então, veio o Lewis Hanke. O Hanke tinha um verdadeiro amor pela América Latina, e colaborou muito.

A grande coisa que fizemos foram os Seminários. Foi o Tannenbaun que os inventou. Era uma coisa meio maluca, no começo. Cada quinta-feira, às quatro horas, reuníamos na sala do Tannenbaun e ele se encarregava (mais ou menos) 
de encontrar um speaker, uma pessoa para apresentar uma conferência a cada semana. Ele partia de um princípio simples: "muitas pessoas passam por Nova lorque e como Deus é brasileiro, sempre haverá alguém para o Seminário" Não havia certeza de nada. Não existia uma programação. Uma vez, eu fui para assistir ao Seminário $e$, assim que apareci na porta, o Tannenbaun disse: "Não tem palestrista para hoje, então quem vai falar é vo$c \hat{e}$ " Mas, de qualquer forma, os Seminários foram se firmando e sempre que o Gilberto Freyre ia para Nova lorque ele falava lá. Viana Nunes estava sempre por perto. Quando o Instituto se estabeleceu, em 60 , a coisa ficou séria e, como eu fui nomeado diretor, é claro, meu interesse foi pelo Brasil. Procurava os melhores alunos e os motivava para ir ao Brasil. Então, o Social Science Research Concil escolheu Columbia como centro de treinamento para pesquisadores interessados no Brasil. Columbia funcionava como um filtro de brasilianistas, e até hoje ainda existem os Seminários, mas já não é como antes. Veja que agora aqui na Flórida nós temos mais ajuda do que eles.

SEBE: /sto quer dizer que ainda hoje a sua figura é que atraiu?

WAGLEY: Não. não é bem assim. . . Temos um grupo muito bom aqui. Eu fui convidado em 71 para vir para cá, e como eu estava chateado com Nova lorque, cansado do frio, do trânsito, da multidão, resolvi que poderia fazer alguma coisa a meu favor, escolhendo um lugar mais calmo para ensinar durante os meus últimos anos. Aí, começamos a criar um pequeno grupo, que está bastante vivo.

SEBE: Seria possivel o senhor definir a ideologia ou o interesse político das fundações em relação ao Brasil?

WAGLEY: Interesses políticos, creio que não. Posso dizer diretamente do meu caso. Eu fui ao Brasil pela primeira vez em 39, com a ajuda da Fundação Rockefeller, que já amparava Columbia. Era uma bolsa de pós-doutorado, para estudar índios. Havia no Brasil grupos interessados e que estavam em contato conosco. No Brasil, a Fundação Rockefeller estava sediada em Manguinhos, desde o começo do século; eles atuaram em 1906, 18 e 24. Eu creio que quem abriu o processo de visitas de especialistas estrangeiros foi a Heloisa Alberto Torres. Ela era a única que não era médico em Manguinhos e ela escreveu a Franz Boas, como diretora do Museu Nacional. Foi ela que conseguiu uma série de bolsas para o Brasil. Também, muitos brasileiros foram auxiliados, principalmente na área de ciências naturais. 
Houve outra fundação importante, a Carnegie. Foi a Carnegie que inovou a educação americana com os centros dirigidos; ela auxiliou Stanford, com estudos de chinês, Harvard, com especialização na União Soviética, e Columbia, com um pouquinho do Brasil.

SEBE: Foram os antropólogos que abriram o caminho no caso brasileiro?

WAGLEY: Foram e sempre com alguns trabalhos originais como a Ruth Landes, com a $\mathbf{C i}$ dade das Mulheres. $\mathrm{O}$ trabalho dela é pioneiro na área de estudos sobre mulheres, homossexuais e candomblé. O caso dela é interessante porque ela saiu de Columbia, se interessou muito pelo Brasil, mas depois desistiu definitivamente. Acho que houve desentendimento entre ela e o Arthur Ramos. Ela era amiga do Edson Carneiro e, como havia diferenças de métodos de trabalho e opiniões científicas, entre os dois, ela acabou por desistir. Eh! Da primeira turma, só eu continuei.

SEBE : E por que, professor?

WAGLEY: Bom, eu casei com uma brasileira, estava encantado com o Brasil, adorei o Brasil desde o princípio. Foi amor à primeira vista e vai ser a última. O Brasil me dava esperanças e sempre me deu sorte. Imagine que na primeira noite que eu cheguei, no famoso Cassino da Urca, eu ganhei duzentos dólares! Eu fiquei no Rio por cinco semanas, foi durante o carnaval, então eu li, estudei português e me diverti muito. Só depois eu embarquei para o Mato Grosso.

SEBE: Como o senhor definiu seu tema de estudos sobre os indios?

WAGLEY: Ah! Foi com a valiosa ajuda do Alfred Métraux. Ele estava em lowa, na Universidade, eu escrevi a ele e ele me deu a indicação. Eu escrevi Ita Amazon Town: a Study of Man in the Tropics depois da Guerra, então eu fiquei dezesseis meses no Rio e voltei para ensinar em Columbia, em 41. Quando eu estava de volta ao Brasil, em 41, ensinando no Museu Nacional, fiz outra pesquisa e encontrei o meu aluno e amigo Eduardo Galvão, que é um dos meus preferidos.

SEBE : Ah! O senhor tem alunos preferidos?

WAGLEY: Tenho sim, e qual é o professor que não tem? O meu mais querido dos brasilianistas é o Ralph della Cava, mas tem também muitos outros.

SEBE: Mas, professor, como um antropólogo pode influenciar tanto historiadores, cientistas politicos e geógrafos?

WAGLEY: Há um certo predomínio de historiadores e cientistas políticos no grupo geral, mas não se esqueça que há 
muitos antropólogos também. Temos o Shepard Forman, o Robert Shirley, não se esqueça do Marvin Harris, que agora ensina em Columbia.

$\hat{E}$ verdade que tem muitos historiadores, mas alguns deles têm vocação antropológica, o Stuart Schwartz, por exemplo, eu gosto muito de um dos primeiros trabalhos dele (Brazil's Portuguese Heritage Shouid Not Be Forgotten), quando ele usa um quadro famoso (Três meninas da mesma rua, de Maria Margarida) para mostrar que a menina india e a negra tém sido estudadas, mas a portuguesa não. Ele tem alma de antropólogo. Mas acho que 0 pai dos historiadores brasileiros não sou eu, é o Stanley Stein, eu o encontrei no Rio, morando lá e fazendo pesquisa antes da Guerra. Ele tem um trabalho muito bom e acho que é dele a paternidade da influência dos novos historiadores brasilianistas.

SEBE: $E$ os intelectuais brasileiros, como se relacionavam com os brasilianistas da primeira geração?

WAGLEY: Bom, vamos marcar a Guerra como período de transição. Antes da Guerra, havia pouco brasileiro que ensinava aqui, ou mesmo que vinha aprender na universidade americana. A influência francesa sempre foi maior e isto aumentou depois que a Missão Francesa foi para compor o grupo da instalação da Universidade de São Paulo. Principalmente a antropologia foi marcada por esta relação, pois a influência de Lévi-Strauss e Roger Bastide foi muito ampla e positiva. A ligação de brasileiros com os norte-americanos se deu muito lentamente $\mathrm{e}$ através de contatos pessoais. O Gilberto Freyre era uma ponte muito importante. O Anísio Teixeira também. O Anísio achava que o sistema educacional americano funcionava bem e por isso devotou estudos sobre a reforma educacional brasileira, voltada para o nosso modelo. Outro brasileiro muito importante, particularmente para mim, foi o Thales de Azevedo; ele ajudou muito e sempre. Ele influenciou marcantemente no grupo que estudou na Bahia, na década de 70. A USP e o Rio nunca foram muito receptores. O Norte e o Nordeste sempre foram muito mais abertos a nós. De São Paulo, ligado à gente, tem o Oracy Nogueira. O Oracy esteve estudando em Chicago e depois estagiou no Museu Nacional do Rio.

SEBE: Professor, como o senhor sabe, Gilberto Freyre é uma figura muito polêmica entre nós, e há uma discussão muito forte em torno do impacto dos Estados Unidos na obra de Freyre, principalmente sobre Casa Grande \& Senzala. Os debates denunciam uma certa 
visão importada do Brasil, que Freyre teria adquirido fora do Brasil.

WAGLEY: Eu não vou analisar Casa Grande \& Senzala, se bem que sempre quero fazê-lo, mas Gilberto Freyre com este livro modernizou as ciências sociais no Brasil, por bom ou mal que o livro seja, ele é pioneiro. Ainda que o Gilberto não tenha feito pesquisas de campo, sem dúvidas ele provocou e ainda excita as mentes de brasileiros. Quando cheguei ao Brasil, em 39, todo mundo, euforicamente, me indicava Casa Grande como a primeira coisa a ler. Li com enorme prazer

\section{SEBE : $O$ senhor leu Casa Grande no Brasil?}

WAGLEY: Li no Brasil porque não tinha chegado, em 39, aos Estados Unidos, e eu não conhecia bem o Brasil, para falar a verdade. Casa Grande sempre teve uma grande influência sobre os brasilianistas, até para os que não concordam. Lembre-se que muitos brasilianistas, como o Skidmore, escreveram sobre este livro, mas tenho certeza que todos reconhecem que esta obra é um divisor de águas. Agora, é verdade que o Gilberto adquiriu muito de seu ponto de vista nos Estados Unidos. Parece que o livro foi pensado em Columbia, ainda que o texto que lá existe, na biblioteca, seja um pequeno trabalho de 25 a
30 páginas, sobre as fazendas brasileiras.

O Tannenbaun manteve um grande respeito, até o fim da vida, por Gilberto. Eu também, mas acho que ultimamente ele está exagerando muito o próprio valor.

SEBE: Professor, se o Gilberto Freyre foi tão importante, então por que tão poucos estudos sobre o Brasil Colonial? Por que os brasilianistas se concentram em estudos sobre a República?

WAGLEY: Isto é mais um problema dos novos brasilianistas, eles é que estão mais próximos da political science. Sabe, um aspecto que sempre me chamou a atenção na cultura acadêmica brasileira foi a sociologia. Sermpre achei que o Florestan é o maior intelectual brasileiro. Respeito muito o trabalho de outros, mas o Florestan sempre foi muito forte. Há também a Maria Isaura, o Antônio Cândido, este é um grupo formidável, até o senador (Fernando Henrique Cardoso) é muito bom. Felizmente, no Brasil não se fala muito da diferença entre antropologia e sociologia, nem de sociologia e história, isto ajuda muito.

SEBE: Quais os projetos importantes do brasilianismo?

WAGLEY: Academicamente, eu acho que o estudo do John 
Wirth, Bob Levine e Joe Love foi muito importante. A contribuição para os estudos regionais dada por eles é significativa, não acha? Tem também a velha mania americana de se estudar as comunidades, aí nós temos uma fila muito comprida com estrelões como o Morse, o Stein, o Warren Dean e até 0 veterano Donald Pierson. Mas ainda acho que o melhor estudo sobre o Brasil ainda é o do della Cava. Você sabe, eu andei muito pelo Brasil e, entre os vários lugares por que passei, visitei Juazeiro, durante a Guerra, voltei colecionando vários livros e sonhei escrever uma obra sobre o padre Cícero, mas no fundo eu sabia que não ia fazê-lo porque não tinha tempo e se tratava de história. Aí, apareceu o della Cava, eu chutei a idéia e ele pegou. Há outra tradição de estudos americanos que é importante para o Brasil, os estudos comparativos, de temas gerais. Neste campo, acho que a escravidão foi o mais importante; gostaria de lembrar aqui - estudo do Carl Degler (Neither Black nor White) e os do Eugene Genovese (Roll, Jordan, Roll. The World Slaveholders Made). Sabe, estes brasilianistas todos são os novos Ewbanks.

SEBE: Bem, professor, nós falamos de aspectos positivos do brasilianismo; agora, eu gostaria de entrar um pouco no ter- reno do negativo. Por que há tanta rejeição ao brasilianismo?

WAGLEY: Vamos começar pela suspeita, sempre se achou que entre os brasilianistas havia gente que trabalhava para a $\mathrm{CIA}$. deve haver, mas eu não conheci ninguém, nunca. Em segundo lugar, como eu defendo a idéia que a vida intelectual não tem fronteira, acho que os brasileiros poderiam vir mais para os Estados Unidos, nos estudar $e$ assim se vingariam de nós e todos ficaríamos felizes.

SEBE: Como o senhor vê o futuro do brasilianismo?

WAGLEY: Tenho vivido vários períodos do brasilianismo. Já vi muita coisa acontecer. Agora estou esperando que haja mais oportunidades para os jovens, pois os velhos já estão nos empregos, e sem perspectivas profissionais não há possibilidade de desenvolvimento de programas. Mas nisto tudo há algo bom: todos sabem que é importante manter estudos sobre o Brasil, veja que às vezes vai gente importante daqui e faz papel feio lá dizendo que está contente por visitar a Bolívia.

SEBE: Quais temas o senhor recomendaria para a nova geração de brasilianistas?

WAGLEY: Ah, o carnaval e o jogo do bicho. Principalmente o 
jogo do bicho, acho que este é o tema melhor para se entender alguns mecanismos internos da alma brasileira. Há outros como o futebol, a roupa, a educação das crianças. Olha, se há uma coisa que não preciso fazer é chutar temas, agora eu tenho já um time que pode ensinar os jovens.
SEBE: Para terminar, professor, o que gostaria de dizer?

WAG LEY: Quero dizer que estou velho e já vivi bastante e que o Brasil sempre foi parte importante da minha existência. Se eu tivesse que viver outra vez queria passar minha vida acadêmica do mesmo jeito, um jeito brasileiro. 